\section{IJ§ER}

ISSN: $2149-5939$
International Journal of Social Sciences and Education Research

Online, http://dergipark.gov.tr/ijsser

\title{
Relevancies to professional development, problems encountered, and rec- ommendations in industrial tours: A student debate
}

\author{
Roberto C. Buenaflor ${ }^{1}$
}

Received Date: 16 / $01 / 2019$

Accepted Date: 25 / 03 / 2019

\begin{abstract}
Education makes no boundaries and is acquired beyond the confines of the classrooms. The study delved into industrial tour relevancies in professional development and the encountered problems of students along educational, sociological, financial, geographical, occupational and psychological components, and also solicited recommendations for tour improvement. It employed debate in obtaining primary qualitative data from logical propositions and arguments of the debating teams. The results disclosed that students enhanced their learning of various machines, tools, and equipment not found in the College. They disliked being brought to industries outside of their specializations and worried about missing the requirements of other classes. They improved interpersonal relationships among students and teachers, gained insights for employment opportunities, and discovered hidden personalities. They suffered immeasurable pressure caused by their desires joining the tour and the needed money that resulted to an abrupt financial constraints of the family. They developed confidence to explore additional places, but emotionally arrested of the amount necessary for the tour plus the pressure of beating deadlines of other class requirements, notwithstanding immeasurable censures from those who refused from joining. In conclusion, the tour was relevant to professional development but a serious psychological arrester on financial and academic concerns. They recommended making the tour part of the curriculum with fund assistance of the College.
\end{abstract}

Keywords: Relevancies, Industrial Tour, Professional Development, Problems and Industrial Technology

\section{Introduction}

Education is a process of creating changes. These changes do not exist in a vacuum but a result of the interplay between and among the internal and external forces of the growing individuals. Educational process, therefore, is not confined to the four-wall arena of learning. It can also be from the environment external of school milieus. Whatever mode is adopted, what is certain is to respond to the educational needs of the learners within their capacities to learn and the means to achieve them. School programs, therefore, have to be designed in a manner that the students are helped to develop and improve their learning potentials. The design shall be in a way that the socio-economic, cultural, and psychological conditions are set within the limits and capabilities of the learners.

This present study is cognizant to the claim of Alexander et al. (2012) that tertiary students are experiencing serious worries about getting employment after graduation. They believe in their insufficient practical skills necessary in the industrial world of work, and that cannot be acquired alone in schools. In said study, they found out the significant association between the industrial training and the employability of the graduates. To underscore this educational concept, the schools are providing industrial tours to allow students gradually explore what they can be best of and how can they prepare and improve for their future.

1Ph.D., robibuenaflor@gmail.com 
Buenaflor, R.C. (2019). Relevancies to professional development, problems encountered, and recommendations in industrial tours: A student debate International Journal of Social Sciences and Education Research, $5(2), 112-121$.

\section{Literature}

Programs and activities in schools have to match with the personal traits and environmental conditions of the learners. A mismatch of these circumstances is likely to be confusing and damaging on the part of the learners and community rather than optimal development and growth. These educational programs may include external activities through educational or industrial tour of the students. This industrial tour is an attempt to bridge the gap between the theoretical field of learning and the practical employment of their skills. The latter is a learning approach that harnesses not only the prevailing talents of the students. It also permits them to discover hidden potentials for any productive work in industries. As the pace of the advancement of science and technology becomes very unpredictable, school curricula are constantly facing a more perplexing challenge of reengineering various programs and activities to meet the increasing demands of the local and global markets. Earley (2016) cited Greany (2015) who advanced this challenge to educational leaders to continually face this challenge with optimism, and that they need to be proactive and collectively build the capacity of synergized values and commitment of meeting international demands of the future.

The tertiary schools are designed not solely to produce graduates to become future employees in any business sector but also to be employers themselves. This points that the curriculum is so designed to develop in the students the skills as workers but also managerial competencies and entrepreneurship. This educational landscape is not strange from the students under study. They are honed to possess a holistic development as managers, leaders, skilled laborers, and entrepreneurs. Along this educational concept, the study of Caggiano, Akabazu, Furfari, and Hageman (2016) espoused the necessity to design and implement a curriculum that secures a systematic facility of teaching-learning processes that develop skills, values, and attitudes towards entrepreneurial undertaking while still in the confines of the school. This training can be enhanced through external venues where they may learn the real things they dream. Hence, a presumption is clear that the school is the preliminary ground where students are developed on the urgent requirements of the workplaces. They are experiencing the learning and training environment that fit to where they should be after graduation. These learning factors does not only limit to materials but also the human resource management that the teachers let them practice. To Borges (2015), the leadership and practices of teachers in the classroom are directly related to the quality of school climate. The interpersonal relationships they develop among others; the safety, equity, and working conditions remarkably constitute the making of favorable learning environment. Imperative of the finding is to have a learning atmosphere established in schools first prior to the exposure of students to the practical working environment in industries, for further professional advancement.

The study of Laguador (2014) underscored the idea that learners who performed in their academic courses, were consistent with their performance in their industrial training program. However, the study does not emphasize the entrepreneurial skills as an aspect of employment. This concept only indicates the coordination of some, and not all, educational programs in the confines of the school and those in the external learning milieus of employment market. In addition, the study of Goh (2011) pointed out that fieldtrips provided enhancement of the education of students and opened gateways for their future careers. 
Buenaflor, R.C. (2019). Relevancies to professional development, problems encountered, and recommendations in industrial tours: A student debate. International Journal of Social Sciences and Education Research, $5(2), 112-121$.

Field trips give the students varied experiences that significantly differ from the daily classroom environment. They can explore new opportunities for advancement, learn hands-on the interactive manner with things and machines, aside from the breather of a monotonous and routine school atmosphere. They develop the skills of planning and looking forward to what to prepare for the trip, and acquire learning in a variety of styles. The trip will allow them to encounter different persons and discover new ideas how to succeed in the future. It can spark new job opportunities, interests, and passions of achieving the desired future, and can develop concern for helping others (Kulas, 2014). To Yusof et al. (2013), exposing the students to industry allows them to learn how to perform their work satisfactorily and enables them to establish a healthy rapport with industrial managers for future employment opportunities.

Exposure of students outside the school learning vicinities is fostering their inclination for entrepreneurial undertakings. Along with this educational concept, Uygun, Mete, and Guner (2015) pointed out that entrepreneurs have the important role in economic growth and development of a country, and that there the motivation of the students are positively related to their intentions of becoming entrepreneurs. The study suggests the idea that on account of business industries to which the technology students are able to visit, they may develop the insights how business parameters look like and the entrepreneurial system operates. In this education program, the industrial tour may devise, or redirect, or enhance their desires to be technologically prepared entrepreneurs. This idea is in accord with the experienced dearth of interactive learning through technological media introduced in the workshops of students. As Yilmaz (2017) underscored the integration of feedbacks as important component of classroom learning, the use of mobile technology provides an effective medium where classroom learning environment becomes interesting and underpins the promotion of student engagement in various learning programs and activities. Despite the emerging fast advancing applications in mobile technology, still the students are seemingly insatiable with what may be available in the social media or may not have the ways to access them.

The impact of using technology in various fields posited much challenge to educational institutions in terms of designing the curriculum to keep learning congruent with the employment industries. Feedback system through representatives of the labor markets appeared to have not significantly contributed to the learning interests of the students, thus they urge of visiting the actual field is for them a must. This interest is aligned to the view of Swift (2010) that stressed that television may be enjoying for the learners, but nothing and nobody can negate the kind of feeling and experience when they are part of the actual setting. He furthered that most schools do not have the sufficiency of the learning equipment and necessary facilities that allow students acquire the practical experience they need to hold upon entrance to gainful employment. However, feedback system from external sources of school is with lesser meaning than the actual learning environment that instructors provide to their students. On this, Bove, Marella, and Vitale (2016) pointed out that learning of students depends on the quality of classroom management where there is more learning engagement of students on content, sufficiency of time in performing assigned tasks, and a climate acceptable behavior of teachers. This puts emphasis that the motivation that students establish while learning in schools is hinged on the kind of learning environment the teachers have on them. This learning arena may include the tools, equipment, visual media, and others that may trigger the interests of the learner to go or not for external milieu of the school setting. Motivation of students in technological areas forms a spe- 
Buenaflor, R.C. (2019). Relevancies to professional development, problems encountered, and recommendations in industrial tours: A student debate International Journal of Social Sciences and Education Research, $5(2), 112-121$.

cial part in learning pace. As Pischetola and Heinsfeld (2018) advanced, there is a valuable connection between the motivational style of teachers and the ways the dialogue-based and democratic classroom space are established through the use of technology. If students are at the disadvantage of sufficient learning of the required competencies in various industries, then they likely opt for exposure in the industries for advancement, tending not to consider problems they may encounter ahead. The industrial tour program in any curriculum is conceived with the importance of knowledge transfer from the experts in practical fields to the students on tour or internship (Peet \& Walsh, 2010).

The above-mentioned studies talked more about connects of classroom climate and learning outside of it, the benefits of industrial training and experiences but failed to underscore the consequential problems that are possibly attached with the tour. Nothing is said about the conduct of industrial tour and the relevancies it produces for student professional development and the trauma upon return to school. Thus, a gap in knowledge has existed between the in-school training and the impact of industrial tour per se. The implementation of industrial tour has created problems for students and teachers in various ways. Issues among others center on the importance of the trip that boils down to its legitimacy as part of the instructional program of the Surigao State College of Technology. This observation prompted the researcher to conduct this investigation among the students, which findings serve as bases for curricular innovation.

\section{Methodology}

The researcher and, at the same time, the professor of Logic of the participants employed a breakthrough of using debate as a new method of gathering data under a qualitative type of research.

\subsection{Participants}

The participants covering six sections with an average of 36 students per section were divided into groups where the members were arbitrarily assigned using counting-off numbers. By odd-even system, all the participants in odd numbers were arbitrarily assigned to the affirmative group and those in even numbers for the negative groups. Purposive sampling of participants were made based on the criteria: 1) they have engaged the industrial tour, and 2) must represent each of the technology specialization.

\subsection{Process}

Each group of 10 members in the debating teams was required to write some arguments or propositions in support to the thesis they are assigned, either pro or against the industrial tour. In a week-long assignment, they were required to submit a copy of their respective logical propositions furnishing their opponents, another group of 10 , to allow time for the latter to refute. Copies of their opposing propositions were presented to the researcher and furnished a copy of the same to their opponents.

The members of the debating team made a choice of a particular issue relative to the industrial tour to focus the arguments and propositions. Each team was required to choose issues relative to the educational, sociological, financial, occupational and psychological components. An open-system of debate was allowed, where other members were permitted to support their teammates in the discussion. Moreover, a free-willing expression of thoughts - even allowing 
Buenaflor, R.C. (2019). Relevancies to professional development, problems encountered, and recommendations in industrial tours: A student debate. International Journal of Social Sciences and Education Research, $5(2), 112-121$

the "dialect" or mother tongue was observed. This system of debate was employed to get a more comprehensive, reliable and valid data from each participant and qualify those found in the documents during rebuttals.

The remaining students in each class were those not able to engage the tour, and acted as observers in the debate. However, these non-members of the debating teams were allowed by the researcher to raise deeper clarifications of the arguments and propositions to scaffold their selfformulated queries. Some relevant responses to their queries by the debating team formed part of the data of the study.

\subsection{Data gathering and analysis}

The researcher objectively accounted the responses of the debating teams by marking the significant arguments, especially those that were not rebutted by the opposing team. The peripheral issues and concerns were also given weights in data recording. They were not informed that the researcher was conducting a study to assure them their natural behavior and setting, and to avoid possible inhibitions and intimidations that may affect the validity and reliability of the data. The researcher made a careful redirection when the speaker tended to shift from one issue to another. The significant facts and circumstances surrounding the issue of each aspect were recorded for the study.

As the study employed the qualitative approach, the analysis of the data were based on the identified areas of professional development and the outlying problems in it. Each uttered issue was recorded and arranged according to the gravity, intensity, and seriousness attached with the word used by the participants in both debating parties. Facial expressions and tonal qualities were also noted in raising arguments. After which, the researcher arranged the data based on the focused areas of professional development and problems. In their respective discourses, the researcher able to get recommendations on improving the industrial tour in terms of its visit in the real thing, including the social, hotel accommodation and meals, and financial concerns. The expressed reasoning and arguments of students were categorized accordingly based on the focused aspects of the study to where they fit best.

\section{Result}

With the control and redirection made, the following were the findings along relevancies of industrial tour to professional development and problems of students, and the recommendations for program improvement. The participants disclosed the relevance of the industrial tour, to wit:

\subsection{On relevancies and problems}

The study arrived at the following relevancies to professional development and the experienced consequential problems of the industrial tour.

\section{Educational component}

The majority of the debating teams claimed that their exposure to various industries has enhanced their learning on the various machines, tools and other industrial equipment not found in the College. Some argued that these can be availed through the use of the internet but was refuted that there is no interactive process with the concerned industrial personnel. The majority 
Buenaflor, R.C. (2019). Relevancies to professional development, problems encountered, and recommendations in industrial tours: A student debate International Journal of Social Sciences and Education Research, $5(2), 112-121$.

of the students also expressed that they were brought to industries that activities have no connections to their fields of specialization.

Although they cannot directly observe the management styles implemented with their industrial personnel, they admitted that they availed the information on the operation management employed by the industries. They also gained knowledge on the layout of their companies in terms of units or sections in accordance with the adopted production system. This finding is aligned with the social learning theory of Bandura, that learning is a significantly complex in process and is influence by a variety of factors where observation plays a critical role in ensuring where, how, and what to learn by growing children (Cherry, 2018). This is to stress that learning takes place anytime and anywhere through observation, imitation, and role modeling.

These participants expressed their serious worries about having failed to meet other requirements in related subjects affected by their absences - like quizzes, projects, and activities. These problems are grounded on the reason that the industrial tour is a based on the technology courses alone. Some of the professors do not also extend extra time for them to cope with the missing requirements as it would also require their extra efforts in preparing another problem and correcting the same with another set of answers.

\section{Sociological component}

The data revealed that the students can socialize with others and win additional friends from among those who joined the tour. Even with old friends, they can spot new strengths and weaknesses of the students in terms of jokes, regard for others and some abilities not observed in school. Although some altercations were experienced in the tour, they found it something to contribute to their learning how to be with others with different personalities. Closer interpersonal relationships with their faculty members were established, and openness was noticed among them. Although they also observe undesirable behaviors among the escorting male teachers, especially when under the influence of liquor, they regarded the same at a tolerable level. They also expressed their discoveries of the hidden personalities of the teachers - as professionals, travel mates, friends, and tour masters.

The tours had allowed them to discover things they disliked of the escorting faculty members having the special table and food reservations. They expressed the feeling of strong gap and socio-cultural discrimination even in this concern. Yan and Kember (2003) viewed these scenarios as a clash among groups of individuals from different strata being exposed to new learning environment outside of their similar school, where the study found out that these different groups have displayed remarkable social coherence to the curriculum, type of teaching, nature of assessment, teacher-student relations, and the learning environment they experience in school. Evident therefore in the tour was the extension of social and cultural ties to other learning environments that they already set while in their respective classrooms.

To a majority, their exposure to various people has contributed to a social concept that different groups of people have their own culture - not only in language. This encounter with other people includes the way they behave in a society, and deal with their fellows and strangers. They discovered that persons from the places they visited have different paces of life as compared to Surigao City, from early morning until sleep. 
Buenaflor, R.C. (2019). Relevancies to professional development, problems encountered, and recommendations in industrial tours: A student debate. International Journal of Social Sciences and Education Research, $5(2), 112-121$

\section{Financial component}

The data revealed the serious sentiments expressed where the participants disclosed the immeasurable pressure created by their desire to go on a tour and to look for money for it. Most of the students divulged how their parents found money to the extent of borrowing at a particular interest rate. They disclosed that pawning some valuable materials, and instant selling of properties were the painful alternatives they made just for the purpose of the tour.

A majority of the respondents claimed that the tour had compelled them to be frugal or responsible for spending money, and has developed in them the importance of giving value of money while away from their respective families. The developed a skill on resisting social pressures on matters involving spending money that were found inconsistent with the purpose of the tour. However, they found financial help from their classmates resulting to the reduction of the accompanying stress on the matter. This finding is aligned with the study of Murray, Lombardi, Bender, and Gerdes (2013) that both forms of social and financial support had positive effects on the adjustments of college students.

The participants expressed that they found no answer as to the financial statements. Accordingly, they paid the amount to the College but as to how their money is spent remained a prevailing question. They also remarked that after the tour, the daily expenditures of the family as to food, allowances and the like, are remarkably reduced so as to recover the abrupt financial demands for the journey. They were not aware of who financed the travels of the faculty members with them in the tour. They also raised the issue that one student in every five is free of expenses for the tour. They are interested to know an answer on how this offer by the tour agency affected their obligated travel expenses. They divulged that they discovered this information from the tour agent but was not disclosed by their respective instructors. They expected that this financial arrangement in the tour could reduce a few of their expenses.

\section{Occupational component}

The participants expressed favor of having observed the actual work of the industrial employees and the kind of working environment. The tour secured them some insights on possible employment opportunities after graduation. It has built them confidence in working in such kind of work and the environment, and had the chance to undergo hands-on activity on machines and other things not found in their classrooms or shops. While some of students asserted that they can also see it in the social media through videos, but prevailing is their desires to go beyond social media and avail practical exposure through multi-modal or blended learning experiences. This finding accords with the study of Ellis, Han, and Pardo (2018) stressing the remarkable variations of student learning through the application of experiential learning and research learning, and which the same are related to their learning outcomes. It puts emphasis that the effective learning best takes place when the learning environment is designed in various ways the students achieve the desired outcomes.

On the other hand, some of them claimed having been brought to the industries where the activities do not relate somehow to their specializations. The participants experienced boredom waiting for some students inside the industry, noting that the activities were interesting only to the students of other specialization. They find the tour a waste of time along this component. 
Buenaflor, R.C. (2019). Relevancies to professional development, problems encountered, and recommendations in industrial tours: A student debate International Journal of Social Sciences and Education Research, 5(2), 112-121.

\section{Geographical component}

For those who traveled for the first time away from the family and Surigao City, the industrial tour has brought them to new places for a change of the environment. They were able to widen their world as the tour developed in them the confidence to go back and the courage to travel to new and different places outside places where they used to. They also claimed to have gained more interests in exploring additional features of other cities and nearby provinces. The change in the learning places appeared to have the increased learning momentum among them. The finding correlates with the study of Kariippanon, Cliff, Lancaster, Okely, and Parrish (2018) that the student-centered learning environments have strong connects to physical learning spaces and the teaching-learning efficacy to student wellbeing.

In addition, the participants expressed their sentiments that prior to the conduct of the tour they were not allowed joining the discussion of the places to visit. They were never solicited of the things or matters they are interested in the tour. They unveiled that they were only informed about the area or city but not the kind of industry and its characteristics. Thus, the visit failed to complement the theoretical aspects of learning in the practical field.

\section{Psychological component}

All the participants agreed that they were all psychologically disturbed when they were informed of the total amount of money they have to pay for the tour. The psychological arrest lasted for two weeks or three and experienced no peace of mind attending to other classes. The emotional warfare was due to the financial capabilities of their parents and the sources to get such fund. The struggle remained until they have finally paid the required amount. These psychologically arresting experiences of the students posited great challenge for resolution among school leaders in imposing educational programs that expose student to new technologies in external learning venues that are incongruent to those experienced in schools. This challenge is in contemplation of the issue: "Can technology help us reinvent how we prepare people for healthy and productive lives?” raised by Bransford, Slowinski, Vye, and Mosborg (2008).

The data also unfolded their experiences upon return having the psychological pressure restored when their daily subsistence for the family and the schooling needs was affected. Cost cutting was imposed in the family, and everybody seemed pointing fingers at the participants of such scenario. Censures from those who failed to join the tours were experienced because of such emotional and financial shortage.

\subsection{Recommendations}

The arguments of the participants recommended that the industrial tour shall be made as an integral part of the curriculum and shall carry an educational unit to avoid abruptly attacking financial pressure of the students. The College shall appropriate financial counterpart for the tour to minimize the financial burden of the parents and students. Sponsoring non-government agencies for the tour are likewise encouraged from among the students and College. It shall be scheduled during semester breaks to avoid incurring absences from and deficiencies in other classes. The industries shall be highly selected and chosen according to the fields of specialization of the students. The financial statement shall be made after the tour. 
Buenaflor, R.C. (2019). Relevancies to professional development, problems encountered, and recommendations in industrial tours: A student debate. International Journal of Social Sciences and Education Research, $5(2), 112-121$.

\section{Conclusions}

The industrial tour is relevant. It offers favorable contributions to the educational, occupational, social and geographic components of student life. However, it causes psychological arrests and emotional pressures not only to the students but also for the parents due to the financial difficulties. Their other classes are affected that resulted in their academic deficiencies and caused them emotionally disturbed. They do not welcome the idea of setting two educational activities at the same time and in different places. There is a must for a more critical review and reengineering process of the Bachelor of Science in Industrial Technology (BSIT) and other related programs of the Surigao State College of Technology that requires industrial tour.

\section{Acknowledgment}

The researcher expresses his sincerest appreciation to the third-year students of the Bachelor of Science in Industrial Technology of the Surigao State College of Technology, Surigao City, for having participated in the debate without reservations. Their freedom of expression during the propositions and arguments during the process are worthy of academic consideration and value.

\section{References}

Alexander, A., William, A., Asaah, J., \& Zakari, A. (2012). The Impact of Students' Industrial Training on their Employability Status after Graduation: Evidence from Kumasi in Ghana. International Journal of Advances in Management and Economics, ISSN: 2278-3369. Retrieved on November 12, 2014, from www.managementjournal.info

Borges, P. (2015). Teaching practices and school climate: The Portuguese students' views. Educational, Cultural and Psychological Studies Journal - 14/2016. doi: 10.7358/ecps-2015-011-borg. Retrieved on 14 January 2019 from http://www.ledonline.it/index.php/ECPS-Journal/article/view/862/687

Bove, G., Marella, D., \& Vitale, V. (2016). Influences of school climate and teacher's behavior on student competencies in mathematics and the territorial gap between Italian macro-areas in PISA 2012. Educational, Cultural and Psychological Studies Journal - 14/2016. doi: 10.7358/ecps-2016-013-bove. Retrieved on 14 January 2019 from http://www.ledonline.it/index.php/ECPS-Journal/article/view/926

Bransford, J., Slowinski, M., Vye, N., \& Mosborg, S. (2008). The learning sciences, technology and designs for educational systems: Some thoughts above change. Lifelong Learning Book Series Vol. 12. 2008. Retrieved on January 16, 2019, from https://link.springer.com/chapter/10.1007/978-1-40208299-3_3

Caggiano, V., Akanazu, H., Furfari, A., \& Hageman, A. (2016). Entrepreneurship education: A global evaluation of entrepreneurial attitudes and values (a transcultural study). Educational, Cultural and Psychological Studies Journal - 14/2016. Doi: 10.7358/ecps-2016-014-cagg. Retrieved on 14 January 2019 from http://www.ledonline.it/index.php/ECPS-Journal/article/view/1069/842

Cherry, K. (2018). How social learning theory works. Accessed on January 15, 2019 from https://www.verywellmind.com/social-learning-theory-2795074

Earley, P. (2016). Global trends and challenges for school leaders: Keeping the focus on learning. Educational, Cultural and Psychological Studies Journal - 14/2016. Doi: 10.7358/ecps-2016-014-earl. Retrieved on 14 January 2019 from http://www.ledonline.it/index.php/ECPSJournal/article/view/1069/842 
Buenaflor, R.C. (2019). Relevancies to professional development, problems encountered, and recommendations in industrial tours: A student debate International Journal of Social Sciences and Education Research, $5(2), 112-121$.

Ellis, R., Han, F., \& Pardo, A. (2018). Measuring engagement in the university student experience of learning in blended environments. Understanding Teaching-Learning Practice. Retrieved on January 16, 2019, from https://link.springer.com/chapter/10.1007/978-981-10-7155-3_8

Goh, E. (2011). The value and benefits of fieldtrips in tourism and hospitality education. Higher learning research communications, Vol. 1 No. 1. Retrieved on November 28, 2014, from file://C:/Users/USER/Downloads/18-136-1-PB\%20 (1).pdf

Kariippanon, K., Cliff, D., Lancaster, S., Okely, A., \& Parrish, A.M. (2018). Perceived interplay between flexible learning spaces and teaching, learning and student wellbeing. Learning Environment Research, Vol. 21 (3), October 2018. Retrieved on January 16, 2019, from https://link.springer.com/article/10.1007/s10984-017-9254-9

Kulas, M. (2014). What are the benefits of field trips for children? Retrieved on December 14, 2914 from http://www.livestrong.com/article/127612-benefits-field-trips-children/

Laguador, J. (2013). Engineering Students' Academic and on-the-Job Training Performance Appraisal Analysis. International Journal of e-Education, e-Business, e-Management and e-Learning, Vol. 3, No. 4, August 2013. Retrieved on November 7, 2014, from http://www.ijeeee.org/Papers/245N00019.pdf

Murray, C., Lombardi, A., Bender, F., \& Gerdes, H. (2013). Social support: main and moderating effects on the relation between financial stress and adjustment among college students with disabilities. Social Psychology of Education, Vol. 16 (2), June 2013. Retrieved on January 16, 2019 from https://link.springer.com/article/10.1007/s11218-012-2904-4

Peet, M., Walsh, K., Sober, R., \& Rawak, C., (2010). Generative knowledge interviewing: A method for knowledge transfer and talent management at the University of Michigan. International Journal of Educational Advancement, Vol. 10 (2), May 2010. doi: 10.1057/ijea.2010.10. Retrieved on January 14, 2019, from https://link.springer.com/content/pdf/10.1057\%2Fijea.2010.10.pdf

Pischetola, M., \& Heinsfeld, B.D. (2018). Technologies and teacher's motivational style: A research study in Brazilian public schools. Educational, Cultural and Psychological Studies Journal - 17/2018. Doi: 10.7358/ecps-2018-017-pisc. Retrieved on 14 January 2019 from http://www.ledonline.it/index.php/ECPS-Journal/article/view/1305

Swift, M. (2010). Learning outside the classroom. ASCD Education Update, 52(10), 2010. Retrieved on January $\quad 13, \quad 2019$, from http://www.ascd.org/publications/newsletters/educationupdate/oct10/vol52/num10/Learning-Outside-the-Classroom.aspx

Uygun, M., Mete, S., \& Guner, E. (2015). The role of entrepreneurial motivation on entrepreneurship intent of youngs. International Journal of Social Sciences and Education Research, 1 (4), 1327-1349. Retrieved on January 8, 2019, from http://dergipark.gov.tr/download/article-file/356162

Yan, L., \& Kember, D. (2003). Influence of the curriculum and learning environment on group learning approaches outside the classroom. Learning Environments Research, Vol. 6 (3) October 2003. Retrieved on January 16, 2019, from https://link.springer.com/article/10.1023/A\%3A1027331908555

Yilmaz, O. (2017). Learner centered classroom in science instruction: Providing feedback with technology integration. International Journal of Research in Education and Science (IJRES), 3(2), 604-613. DOI: $\quad 10.21890 /$ ijres.328091. Retrieved on $10 \quad$ January 2019 from https://files.eric.ed.gov/fulltext/EJ1148424.pdf

Yusof, N.A., Fauzi, S.N., Abidin, N.Z., \& Awang, H. (2013). Improving Graduates’ Employability Skills through Industrial Training: Suggestions from Employers. Journal of Education and Practice, Vol. 4, No. 4. ISSN 2222-1735. Retrieved on November 25, 2014 from http://www.iiste.org/Journals/index.php/JEP/article/view/4513 